\title{
Natural Palygorskite as an Industrial Dye Remover in Single and Binary Systems
}

\author{
Marcos Pereira da Silva ${ }^{a}$, Maria do Socorro Ferreira Santos ${ }^{a}$, Maria Rita Moraes Chaves Santos ${ }^{a}$, \\ Luiz de Sousa Santos Júnior ${ }^{a}$, Maria Gardênnia da Fonseca ${ }^{b}$, Edson Cavalcanti da Silva Filho * \\ ${ }^{a}$ Interdisciplinary Laboratory of Advanced Materials - CCN, Federal University of Piaui - UFPI, \\ 64049-550, Teresina, Piaui, PI, Brazil \\ ${ }^{b}$ Chemistry Department - CCEN, Federal University of Paraíba, 58059-970, João Pessoa, PB, Brazil
}

Received: July 31, 2015; Revised: June 21, 2016; Accepted: August 11, 2016

\begin{abstract}
Layered or fibrous clay minerals are used as adsorbents because they have good performance to remove inorganic and organic species. In this work, a Brazilian fibrous clay mineral was applied to remove Remazol Yellow GR industrial dye from simple and binary systems; this was performed in the presence of lead in the latter case. The adsorption efficiency was investigated under various conditions of $\mathrm{pH}$, time, temperature and dye concentration. The experimental data were fitted to the kinetic pseudo-first- and pseudo-second-order models, and the isotherms were fitted to the Langmuir and Freundlich models. The maximum adsorption capacity was $20.08 \mathrm{mg} \mathrm{g}^{-1}$ at $\mathrm{pH} \mathrm{2,} 240$ minutes and $298 \mathrm{~K}$, and these data were better fit by the kinetic pseudo-second-order model. The equilibrium study was fitted to the Langmuir model at $298 \mathrm{~K}$ and Freundlich for other temperatures and binary systems. The dye sorption in the presence of lead was decreased to $15 \mathrm{mg} \mathrm{g}^{-1}$. Therefore, palygorskite behaved as a promising solid for treating effluents.
\end{abstract}

Keywords: palygorskite, adsorption, industrial dye, binary systems

\section{Introduction}

Environmental problems arise mainly from anthropic actions, during the exploration of natural resources and/or the processing of synthetic materials in the industry, and the consequence is unfavorable changes in ecosystems ${ }^{1}$.

Pollution control, particularly in the textile industries, is highly problematic due to the difficulty in purifying wastewater with a high content of dyes in the liquid effluents. The presence of dyes in water, although not always toxic, is harmful to its aesthetics; therefore, it is a type of visual pollution. Additionally, colorful effluents prevent light transmission for photosynthesis, causing ecological chaos, including in the food chain, which is by far the most critical of the effects produced ${ }^{2,3}$. The chemical substances responsible for the changed water color may also be harmful to human health, causing mutations, cancer, allergies and skin burns ${ }^{4,5}$.

Dyes have complex aromatic structures ${ }^{6}$ containing chromophore groups, which produce color, and auxochromes, which interact with the textile fibers ${ }^{7}$. In general, the dyes used in industries include acid, basic, direct, sulfurous, reactive, disperse, and $\mathrm{azo}^{8}$, and the final category is more widely applied ${ }^{9}$. The complex structure of dyes is stable and not sensitive to biodegrade ${ }^{6}$.

The anionic dyes are distinguished by their negative charge $^{10}$. Despite having several classes (azo, anthraquinone) and types (reactive, acid and azo) with distinct peculiarities

* e-mail: edsonfilho@ufpi.edu.br in their structures, they share as a common characteristic the solubility favored by the presence of the ionic substituents ${ }^{11}$.

The adequate treatment of industrial effluent disposal is necessary to reuse the water; therefore, studies have been conducted aiming to obtain adequate materials and methods from the environmental and economic perspectives with optimal dye removal capacity. As a result, several techniques have been used to treat colored wastewater, e.g., flocculation, coagulation, filtration, oxidation $\left(\mathrm{O}_{3}, \mathrm{UV}, \mathrm{H}_{2} \mathrm{O}_{2}\right)$, and processes using membranes, electrochemistry, photocatalytic oxidation and adsorption ${ }^{12}$. The advantages and disadvantages of each technique have been intensively studied, and adsorption is regarded as an efficient and economic process to remove dyes and pigments ${ }^{13}$.

Adsorption is the accumulation of one or more parts in an interfacial layer, and it may occur by chemisorption or physisorption ${ }^{14,15}$. Various materials are used as adsorbents, e.g., chitosan ${ }^{16,17}$, chitin $^{18}$, soybean oil ${ }^{19}$, material based on cyclodextrin $^{20}$, agricultural wastes ${ }^{21,22}$, cellulose ${ }^{23,24}$, and clay minerals ${ }^{25,26,27}$, among others.

Among these materials, clay minerals are very interesting solids because they are natural, abundant, easily extractable, usually nontoxic, and relatively inexpensive. They also have properties, e.g., mechanical-thermal-chemical stability, and their surface can be chemically modified. Their reactivity and pore structure usually determine the optimal adsorption capacity of these materials ${ }^{28}$. Among the clay minerals, palygorskite is a hydrated magnesium silicate with a fibrous morphology and cell unit composition [( $\mathrm{Mg}, \mathrm{Al}$, 
$\left.\mathrm{Fe})_{5}(\mathrm{Si})_{8} \mathrm{O}_{20} \mathrm{OH}\right)_{2}\left(\mathrm{H}_{2} \mathrm{O}\right)_{4} \cdot \mathrm{nH}_{2} \mathrm{O}^{29-31}$. Its structure has zeolitic water weakly bound to the micro-channels, structural water together with coordination water bonded to ions $(\mathrm{Mg}, \mathrm{Al})$ in the limits of each octahedral layer, and hydroxyl groups (e.g., $\mathrm{Al}-\mathrm{OH}$ and $\mathrm{Mg}-\mathrm{OH})^{32-34}$. Due to the inversion in the tetrahedral silica sheet, the structure of palygorskite has parallel channels in the form of micro-tubes, providing a higher surface area and consequently an excellent adsorption capacity $^{34}$. Therefore, these physical-chemical properties make palygorskite suitable to be used for the sorption of ions and dyes ${ }^{35-37}$ as well as other organic contaminants ${ }^{38-40}$.

In this work, natural palygorskite was used to remove an industrial dye from an aqueous solution. First, the clay mineral sample was characterized by chemical analysis, X-ray fluorescence (XRF), X-ray diffraction (XRD), Fourier transform infrared spectroscopy (FTIR), scanning electron microscopy (SEM) and $\mathrm{N}_{2}$ adsorption/desorption measurements. Next, adsorption experiments were performed to evaluate the effects of time, $\mathrm{pH}$, dye initial concentration, and temperature. Kinetic and equilibrium models were fitted to the experimental adsorption data. The influence of lead on the dye removal was investigated.

\section{Materials and Methods}

\subsection{Chemicals and materials}

Sodium hydroxide (Synth), ethanol P.A. (Synth), potassium nitrate (Vetec), hydrochloric acid (Sigma), and lead nitrate, $\mathrm{Pb}\left(\mathrm{NO}_{3}\right)_{2}$ (Vetec) in analytical grade were used without further treatment. The Brazilian clay mineral sample originated from Guadalupe city, state of Piauí, where it was size-separated in a 200-mesh sieve. Remazol Yellow GR dye was supplied by Brazilian company Dystar Ltda. Deionized water was used in all preparations.

\subsection{Characterizations}

Semi-quantitative chemical analysis was performed in an X-ray fluorescence spectrometer model BOL-FRX. The results were expressed in oxides percentage (\%), which was normalized to $100 \%$. Initially, the samples were prepared by fusion in a borate mixture $\left(\mathrm{Li}_{2} \mathrm{~B}_{4} \mathrm{O}_{7}-\mathrm{LiBO}_{2}\right)$ in a $1: 10 \mathrm{w} / \mathrm{w}$ proportion. X-ray diffraction was performed on a Shimadzu XR-D600A diffractometer, in the $2 \theta$ range of 5 to $60^{\circ}$. The scanning rate was $5^{\circ} \mathrm{min}^{-1}$, using the radiation source $\mathrm{CuK} \alpha$, at a wavelength of $1.54 \AA$. The infrared spectrum was analyzed on an FTIR Bomem spectrophotometer, series MB, by the $\mathrm{KBr}$ pellet method containing $1 \%$ of the sample, in 96 scans, in the 4000-400 $\mathrm{cm}^{-1}$ range at a resolution of $4 \mathrm{~cm}^{-1}$. The morphology of the clay particles was analyzed by Scanning Electron Microscopy, after the metallization of the samples with gold and palladium on the JEOL T-300 microscope. The specific surface area was measured by the Quantacrome
NOVA 4200 analyzer through nitrogen adsorption/desorption measurements. The dye concentration was determined on the Varian CARY 300 UV/VIS Spectrophotometer.

\subsection{Point of zero charge ( $p H P Z C$ )}

The point of zero charge was determined by the powder addition method ${ }^{41,42}$. A $50 \mathrm{mg}$ aliquot of the palygorskite was suspended in $50.0 \mathrm{~mL}$ of $0.001 \mathrm{~mol} \mathrm{~L}^{-1} \mathrm{NaCl}$ solutions. The

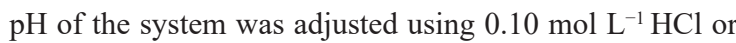
$\mathrm{NaOH}$ aqueous solution. The suspensions were then shaken and allowed to equilibrate for $24 \mathrm{~h}$, after which the $\mathrm{pH}$ of the supernatant was measured. The $\mathrm{pH}$ variation $\left(\Delta \mathrm{pH}=\mathrm{pH}_{\mathrm{f}}-\mathrm{pH}_{\mathrm{i}}\right)$ was plotted against the $\mathrm{pH}_{\mathrm{i}}$, and the point of intersection of the resulting curve at which $\Delta \mathrm{pH}=0$ was the $\mathrm{pH}_{\mathrm{PZC}}$ value.

\subsection{Adsorption Tests}

\subsubsection{Adsorption Kinetics}

In the kinetic study of Remazol Yellow GR dye removal, $30.0 \mathrm{~mL}$ of the $1000 \mathrm{mg} \mathrm{L}^{-1}$ solution of the dye was transferred to a series of Erlenmeyer flasks containing approximately 30.0 $\mathrm{mg}$ of the adsorbent, in a solution whose natural $\mathrm{pH}$ was 6.2 . Next, the suspension was shaken at the temperature of $298 \pm$ $2 \mathrm{~K}$ in time intervals of 15-300 min. After the pre-established intervals, the supernatant was separated by centrifugation at $3500 \mathrm{rpm}$ for $10 \mathrm{~min}$ in a centrifuge (Centribio 80-2B). The dye concentration in the solution, for each time interval, was determined by UV-Vis Spectroscopy (Varian CARY ${ }^{\circledR}$ 300 ) at $414 \mathrm{~nm}$, which corresponds to the maximum dye adsorption. The adsorption capacity of the adsorbent (q) was calculated by the Equation $1^{13}$,

$$
q=\frac{\left(C_{i}-C_{f}\right) V}{m}
$$

where $\mathrm{q}\left(\mathrm{mg} \mathrm{g}^{-1}\right)$ is the adsorbed quantity per gram of adsorbent; $\mathrm{Ci}$ and $\mathrm{C}_{\mathrm{f}}\left(\mathrm{mg} \mathrm{L}^{-1}\right)$ are the concentrations before and after adsorption, respectively; $\mathrm{V}(\mathrm{L})$ is the solution volume; and $\mathrm{m}(\mathrm{g})$ is the adsorbent mass.

The sorption data were fitted to two kinetic models. The linear form of the pseudo-first-order rate equation in integrated form is described by Equation $2^{43}$,

$$
\log \left(q_{e, \text { exp }}-q_{t}\right)=\log q_{e, c a l}-\frac{K_{1}}{2.303} t
$$

where $\mathrm{q}_{\mathrm{e}, \exp }\left(\mathrm{mg} \mathrm{g}^{-1}\right)$ is the quantity adsorbed per gram of adsorbent in the equilibrium, $\mathrm{q}_{\mathrm{e}}$ 'cal $\left(\mathrm{mg} \mathrm{g}^{-1}\right)$ is the adsorbed theoretical quantity per gram of adsorbents, $\mathrm{q}_{\mathrm{t}}\left(\mathrm{mg} \mathrm{g}^{-1}\right)$ is the adsorbed quantity per gram of adsorbent in the time $\mathrm{t}$ ( $\mathrm{min}$ ), and $\mathrm{k}_{1}\left(\mathrm{~min}^{-1}\right)$ is the rate constant of the pseudo-first-order. By plotting $\log \left(q_{e, e x p}-q_{t}\right)$ versus $t$, it is possible to calculate 
the parameters of the pseudo-first-order equation, $\mathrm{q}_{\mathrm{e}, \mathrm{cal}}$ and $\mathrm{k}_{1}$, using the angular and linear coefficients.

The pseudo-second-order model is described by Equations $3^{44,45}$ :

$$
\frac{t}{q_{t}}=\frac{1}{K_{2} q_{e, c a l}^{2}}+\frac{1}{q_{e, c a l}} t
$$

Under the established conditions, the rate constant $k_{2}$ and the theoretical equilibrium sorption capacities $q_{\text {ecal }}$ were calculated from the slopes and intercepts of the linear plots of the pseudo-second-order kinetic model.

\subsubsection{Influence of $\mathrm{pH}$}

The $\mathrm{pH}$ influence on the Remazol Yellow GR dye removal was verified by testing of the $1000 \mathrm{mg} \mathrm{L}^{-1}$ Remazol Yellow GR dye solution at values $\mathrm{pH}$ of 2, 3, 5, 7, 9 and 10, using $0.1 \mathrm{~mol} \mathrm{~L}^{-1} \mathrm{HCl}$ and/or $\mathrm{NaOH}$ solutions. Next, $30.0 \mathrm{~mL}$ aliquots of each solution and $30.0 \mathrm{mg}$ solid were transferred to Erlenmeyer flasks to shake in a thermostatic bath for $240 \mathrm{~min}$ at $298 \pm 2 \mathrm{~K}$. Then, the suspension was centrifuged at 3500 rpm for $10 \mathrm{~min}$. The dye concentrations in the supernatant were determined using the UV-Vis Spectrophotometer. The quantity of the dye adsorbed was calculated by Equation 1 .

To verify any alteration in the dye structure, the dye solution was analyzed at different $\mathrm{pH}$ by UV-Vis spectroscopy at previously described conditions.

\subsubsection{Adsorption isotherms}

The adsorption isotherms were obtained at 298, 308 and $318 \mathrm{~K}$. The used dye solutions were in the range $100-500 \mathrm{mg}$ $\mathrm{L}^{-1}$, all adjusted to $\mathrm{pH} 2.0$, which was previously determined to be the optimal $\mathrm{pH}$. Thus, $30.0 \mathrm{mg}$ of the adsorbent was suspended in $30.0 \mathrm{~mL}$ of each solution and the system was agitated in a thermostatic bath at the pre-established time. After the equilibrium time, the dye concentration of supernatant was quantified. The experimental adsorption data were fitted to the Langmuir and Freundlich models.

The Langmuir model assumes monolayer formation at homogeneous sites of the adsorbent. The maximum adsorption capacity $\left(\mathrm{q}_{\mathrm{m}}\right)$ was calculated using the linear form of the Langmuir equation (Eq. 4). $R_{L}$ is a parameter that indicates if the process was favorable or unfavorable, and it was obtained using Equation $5^{46}$ :

$$
\begin{aligned}
\frac{C_{e}}{q_{e}} & =\frac{1}{K_{L} q_{m}}+\frac{C_{e}}{q_{m}} \\
R_{L} & =\frac{1}{\left(1+K_{L} C_{e}\right)}
\end{aligned}
$$

where $\mathrm{q}_{\mathrm{m}}\left(\mathrm{mg} \mathrm{g}^{-1}\right)$ is the maximum adsorption capacity for the formation of the monolayer; $\mathrm{C}_{\mathrm{e}}\left(\mathrm{mg} \mathrm{L}^{-1}\right)$ is the dye concentration in the equilibrium solution; $\mathrm{K}_{\mathrm{L}}$ is the Langmuir adsorption constant, which involves the adsorption energy; and $\mathrm{q}_{\mathrm{e}}\left(\mathrm{mg} \mathrm{g}^{-1}\right)$ is the maximum adsorption capacity.

The Freundlich model is applied to a heterogeneous surface and the formation of multi-layers. Its linear form is defined by Equation $6^{47}$ :

$$
\log q_{e}=\log K_{F}+\frac{1}{n_{F}} \log C_{e}
$$

where $\mathrm{q}_{\mathrm{e}}$ represents the maximum adsorbed capacity in the equilibrium, $\mathrm{C}_{\mathrm{e}}$ is the equilibrium concentration, $\mathrm{K}_{\mathrm{F}}$ is the adsorption constant related to the bonding energy and $\mathrm{n}_{\mathrm{F}}$ is associated with the surface heterogeneity.

\subsubsection{Influence of $\mathrm{Pb}^{2+}$ ion on the dye adsorption}

Adsorption was verified for a binary mixture (yellow dye and lead) at the same optimized conditions as the single experiments. Thus, $30.0 \mathrm{mg}$ and $30.0 \mathrm{~mL}$ of the binary solution (dye or metal) at each substance concentration of 100 to $1000 \mathrm{mg} \mathrm{L}^{-1}$ were transferred to Erlenmeyer flasks, and the suspension was shaken in a thermostatic bath. The dye concentration was determined as described above.

\section{Results and Discussion}

\subsection{Characterization}

X-ray Fluorescence data on the natural palygorskite showed the following chemical composition expressed in oxide percentage: $\mathrm{MgO}(8.28 \%), \mathrm{Al}_{2} \mathrm{O}_{3}(11.48 \%), \mathrm{SiO}_{2}$ (63.67\%), $\mathrm{Fe}_{2} \mathrm{O}_{3}(3.27 \%), \mathrm{TiO}_{2}(0.87 \%), \mathrm{K}_{2} \mathrm{O}(0.32 \%), \mathrm{MnO}$ $(0.21 \%)$. The fire loss was $11.90 \%$, which is related to loss of water and organic matter. These data were consistent with the palygorskite formula $\left(\mathrm{Si}_{8.05}\right)\left(\mathrm{Al}_{1.74} \mathrm{Fe}_{0.32} \mathrm{Ti}_{0.084} \mathrm{Mn}_{0.023} \mathrm{Mg}_{1.59}\right)$ $\left(\mathrm{K}_{0.052}\right) \mathrm{O}_{20}(\mathrm{OH})_{2}\left(\mathrm{OH}_{2}\right)_{4} \cdot 4 \mathrm{H}_{2} \mathrm{O}$. This result is consistent with the proposed formula ${ }^{48}$.

The diffractograms of the natural palygorskite before and after the sorption of Remazol Yellow GR dye are shown in Figure 1i. The reflections were indexed with the JCPDSICCD crystallographic cards 31-0783 (palygorskite) and 85-0794 (quartz). The XRD of the pristine palygorskite shown typical indexed planes (110), (040), (121) and (161). The XRD patterns are similar to the ones published by Frini-Srasra and collaborators ${ }^{48}$. After the dye sorption, some alterations in the intensity of the (110), (040), (121) and (161) crystallographic planes were clearly observed. Evaluation of the crystallinity was accomplished based on the ratios of the intensity of the reflection of the palygorskite phase and the quartz one, $\left(\mathrm{I}_{\text {quartz }} / \mathrm{I}_{\text {clay }}\right)$ before and after dye interaction as shown in Table 1. A significant change in ratios was observed for the sample after dye sorption, suggesting an alteration in the original crystallinity of the inorganic matrix as the dye removal occurs. 

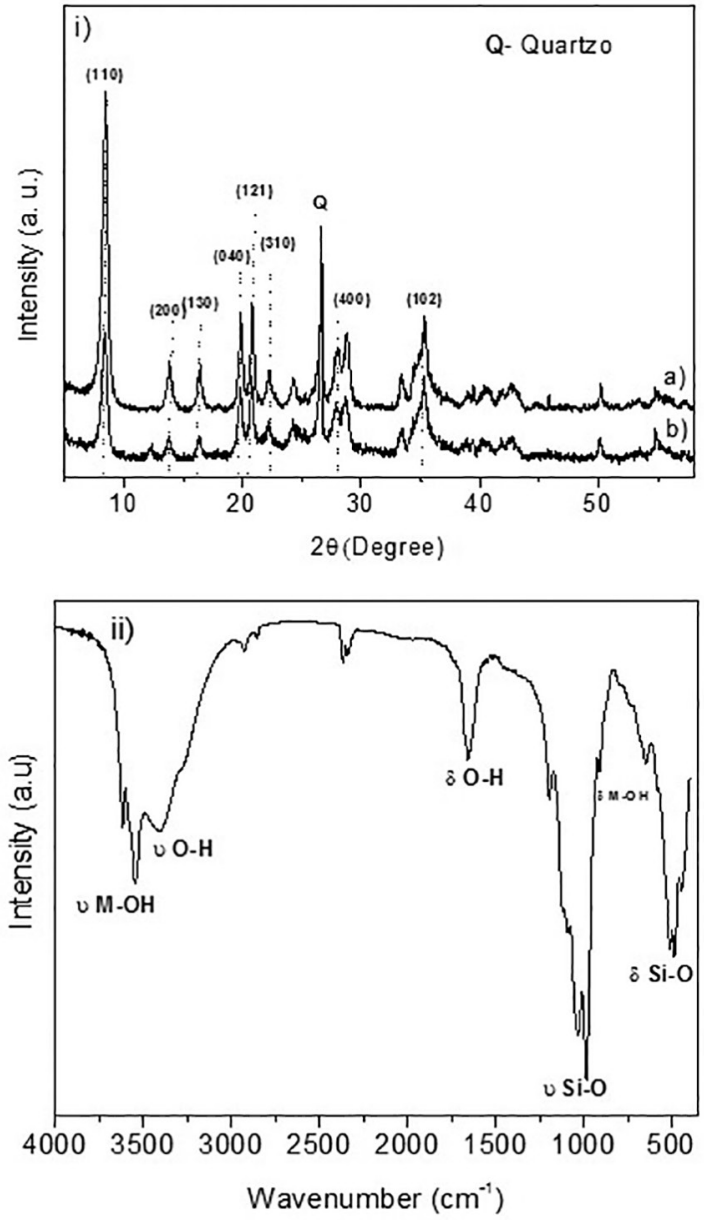

Figure 1: i) X-ray diffractogram of natural palygorskite before (a) and after (b) dye adsorption ii) Infrared spectrum of natural palygorskite.

Table 1: Estimation of the ratios of the intensity of some reflections of the palygorskite and the quartz phase $\left(I_{\text {quartz }} / I_{P}\right)$ before and after dye retention.

\begin{tabular}{lcc}
\hline & \multicolumn{2}{c}{$I_{\text {quartz }} / I_{P}$} \\
Reflection & Before & After \\
\hline 110 & 0.50 & 2.12 \\
200 & 2.37 & 80.73 \\
130 & 2.46 & 63.74 \\
040 & 1.41 & 4.54 \\
121 & 1.30 & 3.74 \\
102 & 1.45 & 5.50 \\
\hline
\end{tabular}

The infrared spectra (Figure 1ii) of the natural palygorskite showed typical absorption bands at 3617 and $3543 \mathrm{~cm}^{-1}$, which were assigned to the stretching of the hydroxyl groups bound to the $\mathrm{Mg}^{2+}$ and $\mathrm{Al}^{3+}$ octahedral cations of the inner surface. The groups are characteristic of the channel ends. The broad band centered at $3405 \mathrm{~cm}^{-1}$ was attributed to the stretching of the $\mathrm{O}-\mathrm{H}$ associated to zeolitic water of the clay mineral ${ }^{49}$. The band centered at $1654 \mathrm{~cm}^{-1}$ was assigned to the bending deformation of the zeolitic water molecules ${ }^{49}$. Typical bands at 1030 and $983 \mathrm{~cm}^{-1}$ were assigned to siloxane stretching, and the bands at 519 and $478 \mathrm{~cm}^{-1}$ were attributed to the vibrational deformation of the $\mathrm{Si}-\mathrm{O}$ group on the tetrahedral sheet ${ }^{50}$. The band at $914 \mathrm{~cm}^{-1}$ was attributed to $\mathrm{M}-\mathrm{OH}$ deformation ${ }^{51}$. These data were fundamental to confirm the palygorskite structure.

The SEM images of the palygorskite (Figure 2) showed the fibrous morphology of the particles ${ }^{52}$.
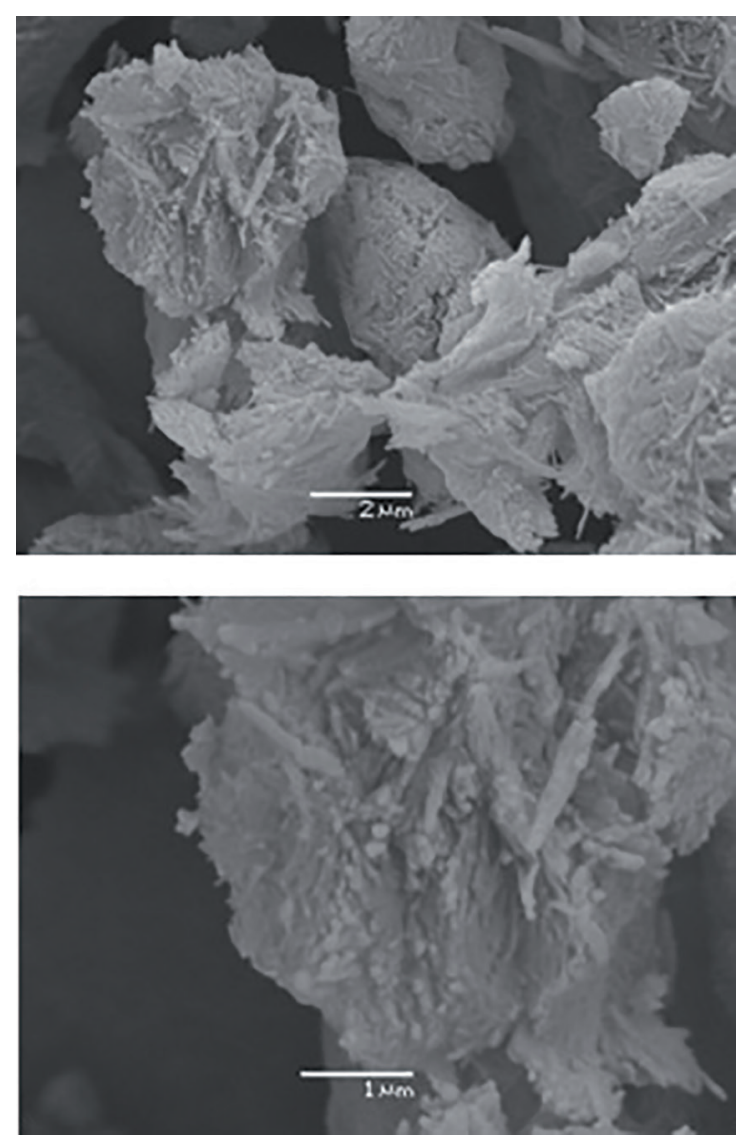

Figure 2: Scanning electron microscopy images of pure palygorskite with different amplifications.

The specific surface area of clay minerals and other materials is one of the most important properties in controlling surface phenomena. Normally microporous and fibrous clay minerals, e.g., sepiolite and palygorskite, and expanded clay minerals have high surface area ${ }^{52,53}$. In this case, the surface area of the natural palygorskite was $113 \mathrm{~m}^{2} \mathrm{~g}^{-1}$, which is consistent with palygorskite samples from Algeria $\left(125 \mathrm{~m}^{2}\right.$ $\left.\mathrm{g}^{-1}\right)^{52}$, Spain $\left(112 \mathrm{~m}^{2} \mathrm{~g}^{-1}\right)^{53}$ and China $\left(119 \mathrm{~m}^{2} \mathrm{~g}^{-1}\right)^{54}$.

\subsection{Dye adsorption}

$\mathrm{pH}_{\mathrm{PCZ}}$ measurements determine the $\mathrm{pH}$ influence on the adsorbent surface by protonation/deprotonation mechanisms ${ }^{5,55,56}$. Thus, acid or basic $\mathrm{pH}$ will interfere 
in the adsorption depending on the systems individual characteristics (adsorbent and adsorbate). Figure 3 shows that the point of zero charge was approximately 8 . In other words, at this $\mathrm{pH}$, the palygorskite surface has zero charge. Therefore, at $\mathrm{pH}$ above 8.0 , the surface will be negatively charged with affinity to cationic species. For $\mathrm{pH}$ lower than 8 , the opposite will occur.

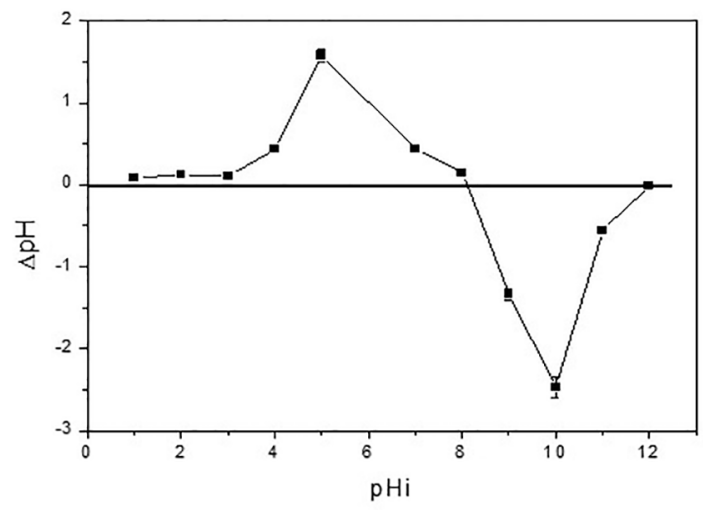

Figure 3: Potential of zero charge for natural palygorskite.

The kinetic study using the natural palygorskite for adsorption of the Remazol Yellow GR dye at $1000 \mathrm{mg} \mathrm{L}^{-1}$ was performed for time points from 15-300 min. As shown in Figure 4, the maximum removal was at an equilibrium time of $240 \mathrm{~min}$. After $300 \mathrm{~min}$, the removal capacity was practically constant. This equilibrium time is a fundamental value in wastewater treatment.

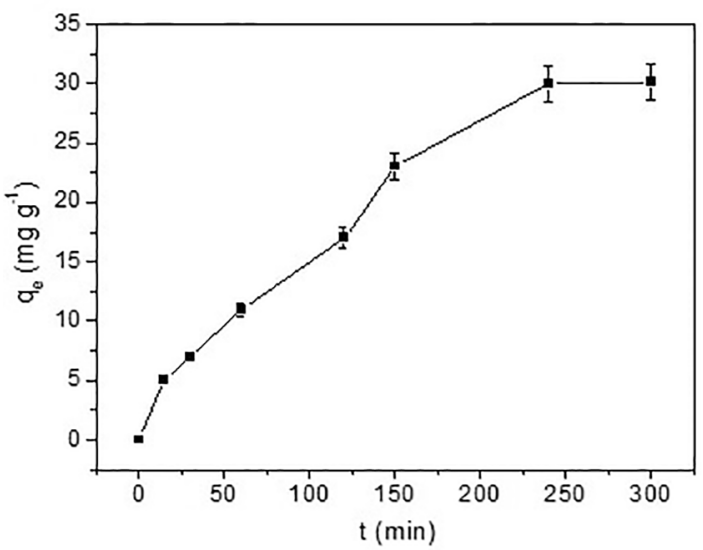

Figure 4: Effect of reaction time on the Remazol Yellow GR dye adsorption of natural palygorskite at $298 \mathrm{~K}$ (Conditions: adsorbent mass of $30 \mathrm{mg}$, dye concentration of $1000 \mathrm{mg} \mathrm{L}^{-1}$ and $\mathrm{pH}$ 6).

The kinetic experimental adsorption data were fitted to the pseudo-first- and pseudo-second-order models. The parameters obtained are shown in Table 2. These data suggest that the adsorption process was described by a pseudo-second-order kinetic, as indicated by the $\mathrm{R}^{2}$ and the low difference between the calculated and experimental maximum capacities, $\mathrm{q}_{\mathrm{e}, \exp }$ and $\mathrm{q}_{\mathrm{e}, \mathrm{cal}}$. Similar results are frequently cited in the literature on dye adsorption ${ }^{5,14}$. The Figure 5 presents the $\mathrm{pH}$ influence on dye-palygorskite interaction. At high $\mathrm{pH}$, Remazol Yellow GR dye removal decreased due to deprotonation of palygorskite, which does not favor interaction with anionic species, such as dye in aqueous solution. At pH 2, the highest dye removal occurred because at lower $\mathrm{pH}$, the palygorskite surface is protonated, which is favorable to its electrostatic interaction with the anionic reactive groups of Remazol Yellow GR $\mathrm{dye}^{57}$. Therefore, based on these results, a dye-clay reaction mechanism in an acid medium was proposed, as shown in Figure 6, whose structure of the dye at $\mathrm{pH} 2$ was determined in software Marwin beans ${ }^{\circledR}$, with $100 \%$ probability of being dissociated species in the finish sulphonic groups, with no other change in the structure. From the results obtained at zero charge potential, it is shown that below $\mathrm{pH} 8$ the clay surface is protonated and as prevailing in the clay groups are hydroxyl groups, these groups is will be protonated, as indicated in Figure 6. The reaction sequence shows the initial solubility of the reactive groups in an acid medium, forming nucleophilic species. As natural palygorskite in acid medium has electrophilic character, the dye-clay electrostatic interaction is predominant.

The UV-Vis spectra of the dye (Figure 7) showed the behavior of Remazol Yellow GR dye absorption after the $\mathrm{pH}$ adjustment (2, 3, 5, 7, 9 and 10). No alteration was observed in the absorptions. The maximum wavelength of Remazol Yellow GR dye after the $\mathrm{pH}$ alteration is the same, and no divergences were detected in the spectra.

The influence of temperature on adsorption is illustrated in Figure 8. The maximum adsorption capacities were 20.08, 15.00 and $15.10 \mathrm{mg} \mathrm{g}^{-1}$ at 298, 308 and $318 \mathrm{~K}$, respectively. These results showed a small influence on the adsorption at higher temperature.

To verify the information collected by the isotherms, it is crucial to fit the experimental data to the physical chemical models because to get a better comprehension of the adsorbate-adsorbent interactions. Table 3 shows the results of fitting to the Langmuir and Freudlinch models for the dye removal on palygorskite in aqueous medium. The data indicated a better fit to the Langmuir model at 298 and to the Freundlich isotherm at 308 and 318 K, with linear increased adjustment to the model Freundlich with increasing temperature, favoring the formation of multilayer and different sites of interaction. These results are consistent with the results of a previous published study ${ }^{56}$.

The adsorption capacity of natural palygorskite for anionic dyes was compared with the adsorption capacities of other adsorbents, as shown in Table 4. These data showed that palygorskite has good potential for removing anionic dye from aqueous solutions. 
Table 2: Parameters obtained from the kinetic fit for adsorption of Remazol Yellow GR dye by natural palygorskite.

\begin{tabular}{lcccccc}
\hline $\begin{array}{l}\mathrm{q}_{\mathrm{e} \text { exp }} \\
\left(\mathrm{mg} \mathrm{g}^{-1}\right)\end{array}$ & $\begin{array}{c}\mathrm{q}_{\mathrm{e}, \text { cal }} \\
\left(\mathrm{mg} \mathrm{g}^{-1}\right)\end{array}$ & $\begin{array}{c}\mathrm{K}_{1} \\
\left(\mathrm{~min}^{-1}\right)\end{array}$ & $\mathrm{R}^{2}$ & $\begin{array}{c}\mathrm{q}_{\mathrm{e}, \text { al }} \\
\left(\mathrm{mg} \mathrm{g}^{-1}\right)\end{array}$ & $\begin{array}{c}\mathrm{K}_{2} \\
\left(\mathrm{mg}^{-1} \mathrm{~min}^{-1}\right)\end{array}$ & $\mathrm{R}^{2}$ \\
\hline 30.00 & 68.62 & 0.0224 & 0.7658 & 48.15 & 1.1933 & 0.9057 \\
\hline
\end{tabular}

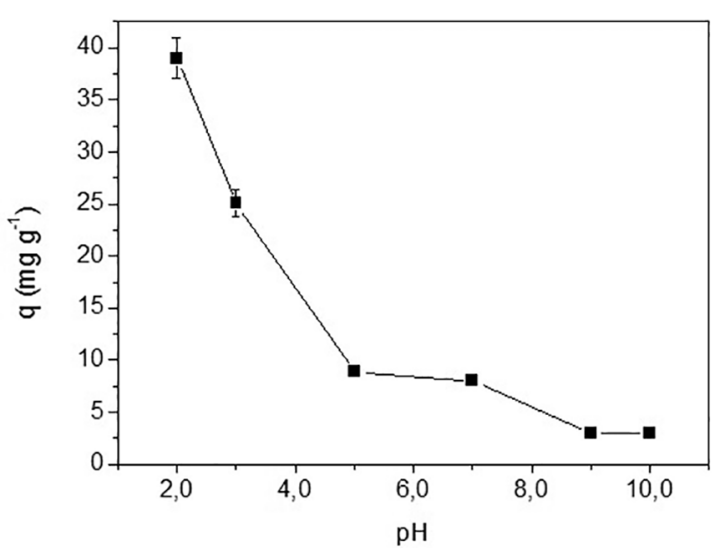

Figure 5: Influence of $\mathrm{pH}$ on yellow dye adsorption by natural palygorskite (Conditions: adsorbent mass of $30 \mathrm{mg}$, dye concentration of $1000 \mathrm{mg} \mathrm{L}^{-1}$ and contact time of $240 \mathrm{~min}$ ).
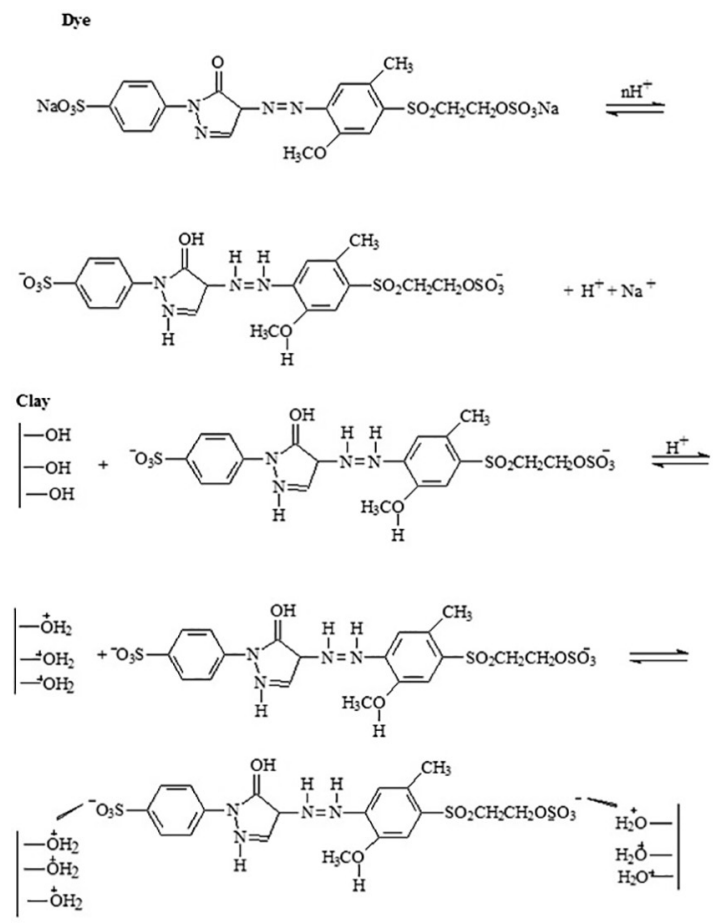

Figure 6: Proposed mechanism for the interaction between Remazol Yellow GR dye and natural palygorskite.

A binary system was used to better understand the dye removal process by natural palygorskite. In this case, the influence of lead was investigated, because it is present in various pigment formulations. Hence, the experimental data presented in Figure 9 indicated that lead decreased

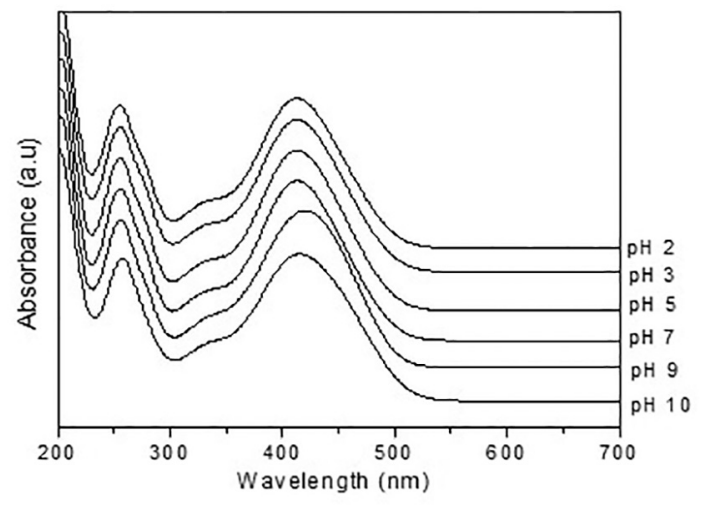

Figure 7: Remazol Yellow GR UV/VIS spectra at $298 \mathrm{~K}$ and different $\mathrm{pH}$ values a) 2, b) 3, c) 5, d) 7, e) 9 and f) 10 .

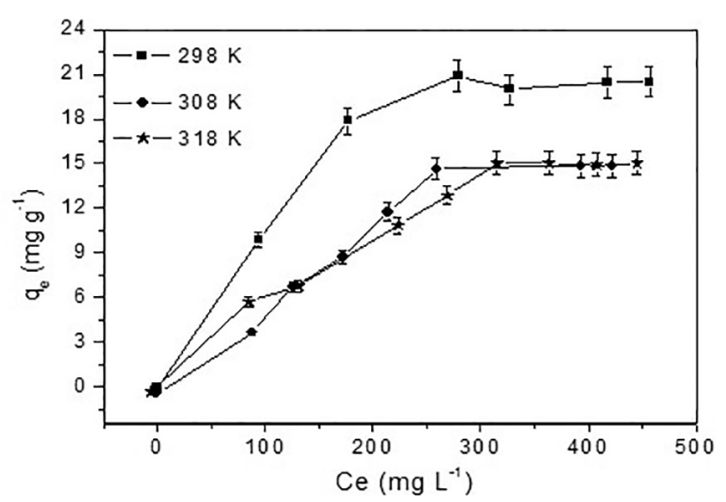

Figure 8: Adsorption isotherms of the Remazol Yellow GR dye by natural palygorskite at different temperatures (Conditions: adsorbent mass of $30 \mathrm{mg}$, dye concentration 100-500 mg L-1, $\mathrm{pH}$ 2 and contact time of $240 \mathrm{~min}$ ).

dye removal to approximately $16 \mathrm{mg} \mathrm{g}^{-1}$. In other words, the preference of adsorption sites for dye molecules was maintained. This result may be due to the preponderance of electrostatic interaction, as discussed previously. The data fits to the Langmuir and Freundlich models are shown in Table 5, showing that the experimental adsorption data were a good fit to the Freundlich model. The $n_{\mathrm{F}}$ parameter was higher than unity, suggesting that the dye/solid interaction was favorable in the presence of lead.

\section{Conclusions}

In this work, the use of natural palygorskite for the removal of anionic dye showed an equilibrium time of 
Table 3: Parameters obtained by the Langmuir and Freundlich isotherms for adsorption of Remazol Yellow GR dye by natural palygorskite.

\begin{tabular}{|c|c|c|c|c|c|c|c|}
\hline \multirow{3}{*}{$\mathrm{T}(\mathrm{K})$} & \multicolumn{7}{|c|}{ Isotherm models } \\
\hline & \multicolumn{4}{|c|}{ Langmuir } & \multicolumn{3}{|c|}{ Freundlich } \\
\hline & $\begin{array}{c}\mathrm{q}_{\text {máx }} \\
\left(\mathrm{mg} \mathrm{g}^{-1}\right)\end{array}$ & $\begin{array}{c}\mathrm{K}_{\mathrm{L}} \\
\left(\mathrm{L} \mathrm{mg}^{-1}\right)\end{array}$ & $\mathrm{R}_{\mathrm{L}}$ & $\mathrm{R}^{2}$ & $\mathrm{n}_{\mathrm{F}}$ & $\begin{array}{c}\mathrm{K}_{\mathrm{F}} \\
\left(\mathrm{L} \mathrm{g}^{-1}\right)\end{array}$ & $\mathrm{R}^{2}$ \\
\hline 298 & 26.81 & 0.0093 & 0.2471 & 0.9383 & 2.27 & 0.6491 & 0.7530 \\
\hline 308 & 40.65 & 0.0016 & 0.7073 & 0.4341 & 1.22 & 0.1249 & 0.8691 \\
\hline 318 & 29.17 & 0.0025 & 0.5356 & 0.8762 & 1.53 & 0.2935 & 0.9499 \\
\hline
\end{tabular}

Table 4: Comparison of different adsorbents for dye removal from aqueous solution.

\begin{tabular}{lccccccc}
\hline Adsorbents & Dyes & Time $(\mathrm{h})$ & $\mathrm{pH}$ & $\begin{array}{c}\text { Concentration } \\
\left(\mathrm{mg} \mathrm{L}^{-1}\right)\end{array}$ & $\begin{array}{c}\text { Dosage- } \\
\text { Adsorbents }(\mathrm{mg})\end{array}$ & $\begin{array}{c}\text { Amount adsorbed } \\
\mathrm{q}_{\mathrm{m}}\left(\mathrm{mg} \mathrm{g}^{-1}\right)\end{array}$ & References \\
\hline Coconut husk & $\begin{array}{c}\text { Violet acid } \\
\text { Acid brillhiant } \\
\text { blue }\end{array}$ & 2 & 2 & 40 & 600 & 1.64 & 56 \\
Banana skin & 1 & 3 & 10 & 400 & 4.42 & 57 \\
Pine ashes & Acid blue & 4 & 6.6 & 200 & 100 & 11.76 & 58 \\
$\begin{array}{l}\text { Peanut husk } \\
\text { Natural } \\
\text { palygorskite }\end{array}$ & $\begin{array}{c}\text { Sunset yellow } \\
\text { Remazol yellow }\end{array}$ & 36 & 2 & 10 & 5000 & 13.99 & 59 \\
\hline
\end{tabular}

Table 5. Parameters obtained by the Langmuir and Freundlich isotherms for the removal of Remazol Yellow GR dye in the presence of $\mathrm{Pb}^{2+}$ ion by natural palygorskite at $298 \mathrm{~K}$ and $\mathrm{pH} 2.0$.

\begin{tabular}{|c|c|c|c|c|c|c|c|c|}
\hline \multirow[t]{3}{*}{$\mathrm{pH}$} & \multirow[t]{3}{*}{$\mathrm{T}(\mathrm{K})$} & \multicolumn{7}{|c|}{ Isotherms models } \\
\hline & & \multicolumn{4}{|c|}{ Langmuir } & \multicolumn{3}{|c|}{ Freundlich } \\
\hline & & $\begin{array}{c}\mathrm{q}_{\max } \\
\left(\mathrm{mg} \mathrm{g}^{-1}\right)\end{array}$ & $\begin{array}{c}\mathrm{K}_{\mathrm{L}} \\
\left(\mathrm{L} \mathrm{mg}^{-1}\right)\end{array}$ & $\mathrm{R}_{\mathrm{L}}$ & $\mathrm{R}^{2}$ & $\mathrm{n}_{\mathrm{F}}$ & $\begin{array}{c}\mathrm{K}_{\mathrm{F}} \\
\left(\mathrm{L} \mathrm{g}^{-1}\right)\end{array}$ & $\mathrm{R}^{2}$ \\
\hline 2 & 298 & 30.28 & 0.0010 & 0.9803 & 0.8795 & 1.33 & 0.0939 & 0.9898 \\
\hline
\end{tabular}

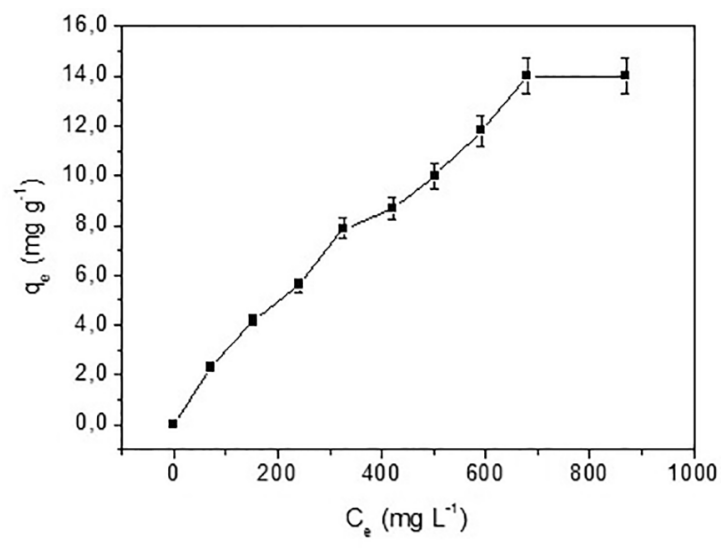

Figure 9: Adsorption isotherms of the Remazol Yellow GR dye by natural palygorskite at different temperatures (Conditions: adsorbent mass of $30 \mathrm{mg}$, dye concentration $100-500 \mathrm{mg} \mathrm{L}^{-1}, \mathrm{pH} 2$ and contact time of $240 \mathrm{~min}$ ) in the binay systems.

$240 \mathrm{~min}$ at $298 \mathrm{~K}$, and the experimental data were fit to a pseudo-second-order kinetic model. Higher dye adsorption was achieved at $\mathrm{pH} 2$ with a preponderance of electrostatic interactions at the dye/solid interface. The temperature influenced adsorption, with maximum removal of 20.08 $\mathrm{mg} \mathrm{g}^{-1}$ at $298 \mathrm{~K}$. The equilibrium data were a good fit to the
Langmuir model at $298 \mathrm{~K}$ and to the Freundlich equation for the other temperatures investigated. The presence of lead in the solution affected the dye removal with a small change in dye retention, $14.00 \mathrm{mg} \mathrm{g}^{-1}$. Therefore, this study demonstrated that natural palygorskite can be used in Remazol Yellow GR dye removal under the investigated conditions.

\section{Acknowledgments}

\section{CAPES, CNPq, UFPI, CETEM and ITAOESTE.}

\section{References}

1. Kunz A, Peralta-Zamora P, Moraes SG, Durán N. New tendencies on textile effluent treatment. Química Nova. 2002;25(1):78-82.

2. Slokar YM, Le Marechal AM. Methods of decoloration of textile wastewaters. Dyes and Pigments. 1998;37(4):335-356.

3. Allen SJ, Gan Q, Matthews R, Johnson PA. Kinetic modeling of the adsorption of basic dyes by kudzu. Journal of Colloid and Interface Science. 2005;286(1):101-109.

4. Cardoso NF, Pinto RB, Lima EC, Calvete T, Amavisca CV, Royer $\mathrm{B}$, et al. Removal of remazol black B textile dye from aqueous solution by adsorption. Desalination. 2011;269(1-3):92-103. 
5. Hamzeh Y, Ashori A, Azadeh E, Abdulkhani A. Removal of Acid Orange 7 and Remazol Black 5 reactive dyes from aqueous solutions using a novel biosorbent. Materials Science and Engineering: C. 2012;32(6):1394-1400.

6. Kayan B, Gözmen B, Demirel M, Gizir AM. Degradation of acid red 97 dye in aqueous medium using wet oxidation and electro-Fenton techniques. Journal of Hazardous Materials. 2010;177(1-3):95-102.

7. Gupta VK, Suhas. Application of low-cost adsorbents for dye removal - A review. Journal of Environmental Management. 2009;90(8):2313-2342.

8. Demirbas A. Agricultural based activated carbons for the removal of dyes from aqueous solutions: A review. Journal of Hazardous Materials. 2009;167(1-3):1-9.

9. Forgacs E, Cserháti T, Oros G. Removal of synthetic dyes from wastewaters: A review. Environmental International. 2004;30(7):953-971.

10. Tyagi OD, Yadav MS. A Textbook of Synthetic Dyes. 1st ed. New Delhi: Anmol Publications Pvt; 2002. 310 p.

11. Hunger K, ed. Industrial Dyes, Chemistry, Properties, Applications. 1st ed. Weinheim: Wiley-VCH; 2003. 648 p.

12. Wang L, Zhang JP, Wang AQ. Fast removal of methylene blue from aqueous solution by adsorption onto chitosan- $g$-poly (acrylic acid)/attapulgite composite. Desalination. 2011;266(1-3):33-39.

13. Silva LS, Lima LCB, Silva FC, Matos JME, Santos MRMC, Santos Junior LS, et al. Dye anionic sorption on aqueous solution onto a cellulose surface chemically modified with aminoethanethiol. Chemical Engineering Journal. 2013;218:89-98.

14. Ponec V, Knor Z, Černý S. Adsorption on solids. $1^{\text {st }}$ ed. London: Butterworth; 1974.

15. Ościk J. Adsorption. $1^{\text {st }}$ ed. New Jersey: John Wiley \& Sons; 1982. $206 \mathrm{p}$.

16. Silva Filho EC, Monteiro PDR, Sousa KS, Airoldi C. Ethylenesulfide as a useful agent for incorporation into the biopolymer chitosan in a solvent-free reaction for use lead and cadmium removal. Journal of Thermal Analysis and Calorimetry. 2011;106(2):369-373.

17. Elwakeel KZ, El-Ghaffar MAA, El-Kousy SM, El-Shorbagy HG. Synthesis of new ammonium chitosan derivatives and their application for dye removal from aqueous media. Chemical Engineering Journal. 2012;203:458-468.

18. Akkaya G, Uzun I, Güzel F. Kinetics of the adsorption of reactive dyes by chitin. Dyes and Pigments. 2007;73(2):168-177.

19. Mittal A, Mittal J, Kurup L. Batch and bulk removal of hazardous dye, indigo carmine from wastewater through adsorption. Journal of Hazardous Materials. 2006;137(1):591-602.

20. Crini G, Peindy HN. Adsorption of C.I. Basic Blue 9 on cyclodextrin-based material containing carboxylic groups. Dyes and Pigments. 2006;70(3):204-211.

21. Djilani C, Zaghdoudi R, Modarressi A, Rogalski M, Djazi F, Lallam A. Elimination of organic micropollutants by adsorption on active carbon prepared from agricultural waste. Chemical Engineering Journal. 2012;189-190:203-212.
22. Mahmoud, DK, Salled MAM, Karim WAWA, Idris A, Abidin ZZ. Batch adsorption of basic dye using acid treated kenaf fibre char: Equilibrium, kinetic and thermodynamic studies. Chemical Engineering Journal. 2012;181-182:449-457.

23. Silva Filho EC, Santos Junior LS, Silva MMF, Fonseca MG, Santana SAA, Airoldi C. Surface cellulose modification with 2-aminomethylpyridine for copper, cobalt, nickel and zinc removal from aqueous solution. Materials Research. 2013;16(1):79-84.

24. Silva Filho EC, Lima LCB, Silva FC, Sousa KS, Fonseca MG, Santana SAA. Immobilization of ethylene sulfide in aminated cellulose for removal of the divalent cations. Carbohydrate Polymers. 2013;92(2):1203-1210.

25. Silva MMF, Oliveira MM, Avelino MC, Fonseca MG, Almeida RKS, Silva Filho EC. Adsorption of an industrial anionic dye by modified-KSF-montmorrilonite: Evaluation of the kinetic, thermodynamic and equilibrium data. Chemical Engineering Journal. 2012;203:259-268.

26. Gil A, Assis FCC, Albeniz S, Korili SA. Removal of dyes from wastewaters by adsorption on pillared clays. Chemical Engineering Journal. 2011;168(3)1032-1040.

27. Li W, Tang Y, Zeng Y, Tong Z, Liang D, Cui W. Adsorption behavior of $\mathrm{Cr}(\mathrm{VI})$ ions on tannin-immobilized activated clay. Chemical Engineering Journal. 2012;193-194:88-95.

28. Bergaya F, Theng BKG, Lagaly G, eds. Handbook of Clay Science. Amsterdam: Elsevier; 2006.

29. Fan Q, Li Z, Zhao H, Jia Z, Xu J, Wu W. Adsorption of Pb(II) on palygorskite from aqueous solution: Effects of $\mathrm{pH}$, ionic, strength and temperature. Applied Clay Science. 2009;45(3):111-116.

30. Liu P, Wang TM. Adsorption properties of hyperbranched aliphatic polyester grafted attapulgite towards heavy metal ions. Journal of Hazardous Materials. 2007;149(1):75-79.

31. Liu Y, Wang WB, Wang AQ. Adsorption of lead ions from aqueous solution by using carboxymethyl cellulose- $g$-poly (acrylic acid)/attapulgite hydrogel composites. Desalination. 2010;259(1-3)258-264.

32. Oldshue JY. Mixing. Industrial Engineering Chemistry. 1967;59(11):58-70.

33. Chisholm JE. Powder-diffraction patterns and structural models for palygorskite. Canadian Mineralogist. 1992;30:61-73.

34. Chiari G, Giustetto R, Ricchiardi G. Crystal structure refinements of palygorskite and Maya Blue from molecular modeling and powder synchrotron diffraction. European Journal of Mineralogy. 2003;15(1):21-33.

35. Fan Q, Shao D, Lu Y, Wub W, Wang X. Effect of $\mathrm{pH}$, ionic strength, temperature and humic substances on the sorption of $\mathrm{Ni}(\mathrm{II})$ to Na-attapulgite. Chemical Engineering Journal. 2009;150(1):188-195.

36. Liu Y, Wang WB, Jin YL, Wang AQ. Adsorption Behavior of Methylene Blue from aqueous Solution by the Hydrogel Composites Based on Attapulgite. Separation Science and Technology. 2011;46(5)858-868.

37. Wang LG, Yan GB. Adsorptive removal of direct yellow 161 dye from aqueous solution using bamboo charcoals activated with different chemicals. Desalination. 2011;274(1-3):81-90. 
38. Huang JH, Liu YF, Wang XG. Selective adsorption of tannin from flavonoids by organically modified attapulgite clay. Journal of Hazardous Materials. 2008;160(2-3):382-387.

39. Frini-Srasra N, Srasra E. Adsorption of quinalizarin from non aqueous solution onto acid activated palygorskite. Surface Engineering and Applied Electrochemistry. 2009;45(4):306-311.

40. Balistrieri LS, Murray JW. The surface chemistry of goethite $(\alpha-\mathrm{FeOOH})$ in major ion seawater. American Journal of Science. 1981;281(6):788-806.

41. Gillman GP. Influence of organic-matter and phosphate content on the point of zero charge of variable charge components in oxidic soils. Australian Journal of Soil Research. 1985;23(4):643-646.

42. Marchi G, Guilherme LRG, Chang AC, Curi N, Guerreiro MC. Changes in isoeletric point as affected by anion adsorption on two Brazilian oxisols. Communication in Soil Science and Plant Analysis. 2006;37(9-10)1357-1366.

43. Lagergren S. Zur Theorie der sogenannten Adsorption gelöster Stoffe. Kungliga Svenska Vetenskapsakademiens. Handlingar. 1898;24(4):1-39.

44. Ho YS, McKay G. Pseudo-second order model for sorption processes. Process Biochemistry. 1999;34(5)451-465.

45. Ho YS. Review of second-order models for adsorption systems. Journal of Hazardous Materials. 2006;136(5):681-689.

46. Langmuir I. The adsorption of gases on plane surfaces of glass, mica and platinum. Journal of the American Chemical Society. 1918;40(9):1361-1403.

47. Freundlich H. Über die Adsorption in Lösungen. Leipzig: Wilhelm Engelman; 1906. 98 p.

48. Temkin MJ, Pyzhev V. Recent modications to Lagmuir isotherms. Acta Physico-Chimica Sinica. 1940;12:217-222.

49. Frini-Srasra N, Srasra E. Acid treatment of south Tunisian palygorskite: Removal of Cd(II) from aqueous and phosphoric acid solutions. Desalination. 2010;250(1):26-34.
50. Liu Y, Wang W, Wang A. Effect of dry grinding on the microstructure of palygorskite and adsorption efficiency for methylene blue. Powder Technology. 2012;225:124-129.

51. Tang Y, Zhang H, Liu X, Cai D, Feng H, Miao C, et al. Flocculation of harmful algal blooms by modified attapulgite and its safety evaluation. Water Research. 2011;45(9)2855-2862.

52. Boudriche L, Calvet R, Hamdi B, Balard H. Effect of acid treatment on surface properties evolution of attapulgite clay: An application of inverse gas chromatography. Colloids and Surfaces A: Physicochemical and Engineering Aspects. 2011;392(1):45-54.

53. Michot LJ, Villieras F. Surface area and porosity. In: Bergaya F, Theng BKG, Lagaly G, eds. Handbook of Clay Science. Amsterdam: Elsevier; 2006. p. 965-978.

54. Álvarez-Ayuso E, García-Sánchez A. Removal of cadmium from aqueous solutions by palygorskite. Journal of Hazardous Materials. 2007;147(1-2):594-600.

55. Kong Y, Yuan J, Wang Z, Yao S, Chen Z. Application of expanded graphite/attapulgite composite materials as electrode for treatment of textile wastewater. Applied Clay Science. 2009;46(4)358-362.

56. Zhang L, Jin Q, Huang J, Liu Y, Shan L, Wang X. Modification of palygorskite surface by organofunctionalization for application in immobilization of $\mathrm{H}_{3} \mathrm{PW}_{12} \mathrm{O}_{40}$. Applied Surface Science. 2010;256(20)5911-5917.

57. Namasivayam C, Prabha D, Kumutha M. Removal of direct red and acid brilliant blue by adsorption on to banana pith. Bioresource Technology. 1998;64(1):77-79.

58. Tseng RL, Wu FC, Juang RS. Liquid-phase adsorption of dyes and fenols using pinewood-based activated carbons. Carbon. 2003;41(3):487-495.

59. Gong R, Ding Y, Li M, Yang C, Liu H, Sun Y. Utilization of powdered peanut hull as biosorbent for removal of anionic dyes from aqueous solution. Dyes and Pigments. 2005;64(3):187-192. 